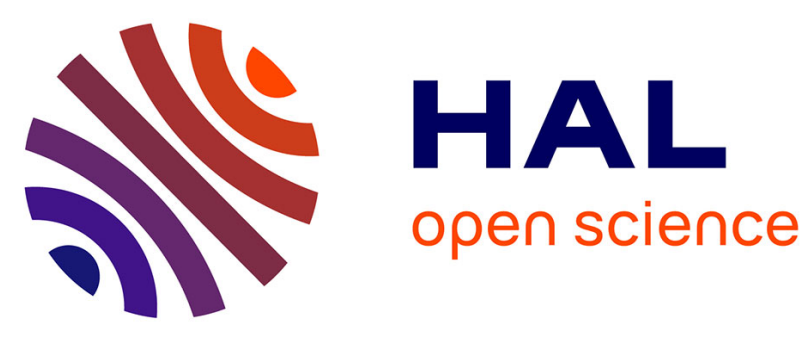

\title{
Nutrition and physical activity: French intergroup clinical practice guidelines for diagnosis, treatment and follow-up (SNFGE, FFCD, GERCOR, UNICANCER, SFCD, SFED, SFRO, ACHBT, AFC, SFP-APA, SFNCM, AFSOS)
}

Cindy Neuzillet, Amélie Anota, A.-M. Foucaut, Anne-Laure Védie, Sami Antoun, Didier Barnoud, Carole Bouleuc, Frédéric Chorin, Vanessa Cottet, Eric Fontaine, et al.

\section{To cite this version:}

Cindy Neuzillet, Amélie Anota, A.-M. Foucaut, Anne-Laure Védie, Sami Antoun, et al.. Nutrition and physical activity: French intergroup clinical practice guidelines for diagnosis, treatment and follow-up (SNFGE, FFCD, GERCOR, UNICANCER, SFCD, SFED, SFRO, ACHBT, AFC, SFP-APA, SFNCM, AFSOS). BMJ Palliative and supportive care, 2021, 11 (4), pp.381-395. 10.1136/bmjspcare-2020002751 . hal-03038521

\section{HAL Id: hal-03038521 \\ https://hal.science/hal-03038521}

Submitted on 18 Dec 2020

HAL is a multi-disciplinary open access archive for the deposit and dissemination of scientific research documents, whether they are published or not. The documents may come from teaching and research institutions in France or abroad, or from public or private research centers.
L'archive ouverte pluridisciplinaire HAL, est destinée au dépôt et à la diffusion de documents scientifiques de niveau recherche, publiés ou non, émanant des établissements d'enseignement et de recherche français ou étrangers, des laboratoires publics ou privés. 


\section{Nutrition and Physical Activity: French Intergroup Clinical Practice Guidelines for diagnosis, treatments and follow-up (SNFGE, FFCD, GERCOR, UNICANCER, SFCD, SFED, SFRO, ACHBT, AFC, SFP-APA, SFNCM, AFSOS)}

Cindy Neuzillet ${ }^{1,{ }^{*}}$, Amélie Anota ${ }^{2, \#}$, Aude-Marie Foucaut ${ }^{3, \#}$, Anne-Laure Védie ${ }^{4, \#,}$, Sami Antoun ${ }^{5}$, Didier Barnoud $^{6}$, Carole Bouleuc ${ }^{7}$, Frédéric Chorin ${ }^{8}$, Vanessa Cottet $^{9}$, Eric Fontaine ${ }^{10}$, Valérie Garabige ${ }^{7}$, Xavier Hébuterne ${ }^{11}$, Florence Huguet ${ }^{12}$, Astrid Lièvre ${ }^{13}$, Timothée Marchal ${ }^{7}$, Thomas Mouillot ${ }^{14}$, Frédérique Peschaud $^{15}$, Didier Quilliot ${ }^{16}$, Bruno Raynard ${ }^{5}$, Stéphane Schneider ${ }^{11}$, Florian Scotté ${ }^{17}$, Damien Vansteene ${ }^{18}$, Pascale Mariani ${ }^{19}$, Olivier Bouché ${ }^{20}$, Francisca Joly ${ }^{21}$, on behalf of the Thésaurus National de Cancérologie Digestive (TNCD), Société Nationale Française de Gastroentérologie (SNFGE), Fédération Francophone de Cancérologie Digestive (FFCD), Groupe Coopérateur multidisciplinaire en Oncologie (GERCOR), Fédération Nationale des Centres de Lutte Contre le Cancer (UNICANCER), Société Française de Chirurgie Digestive (SFCD), Société Française d'Endoscopie Digestive (SFED), Société Française de Radiothérapie Oncologique (SFRO), Association de Chirurgie Hépato-BilioPancréatique et Transplantation (ACHBT), Association Française de Chirurgie (AFC), Société Française des Professionnels en Activité Physique Adaptée (SFP-APA), Société Francophone de Nutrition Clinique et Métabolisme (SFNCM), Association Francophone pour Soins Oncologiques de Support (AFSOS)

"Contributed equally

*Corresponding author:

Dr. Cindy Neuzillet, Department of Medical Oncology, Curie Institute Versailles Saint-Quentin University (UVSQ) - Paris Saclay University, 35 rue Dailly, 92210 Saint-Cloud, France. E-mail: cindy.neuzillet@curie.fr; Tel:+33 (0)682550492. 
Affiliations:

1. Department of Medical Oncology, Curie Institute, Versailles Saint-Quentin University (UVSQ) - Paris Saclay University, Saint-Cloud, France

2. Methodology and Quality of Life Unit in Oncology, University Hospital of Besançon, University Bourgogne Franche-Comté, Inserm, EFS BFC, UMR 1098, Interactions Hôte-GreffonTumeur/Ingénierie Cellulaire et Génique, Besançon, France; Biostatistics Unit, DRCI, Centre Léon Bérard, Lyon, France

3. Université Sorbonne Paris Nord, Laboratoire Educations et Pratiques de Santé, LEPS UR 3412, Bobigny, France

4. Department of Gastroenterology and Pancreatology, Beaujon University Hospital (CHU), Assistance Publique-Hôpitaux de Paris (AP-HP), Paris 7 Diderot University, Clichy La Garenne, France

5. Nutrition and Readaptation Unit-Gustave Roussy-Cancer Campus, Chevilly-Larue, France

6. Department of Intensive Clinical Nutrition, Hospices Civils de Lyon (CHU Lyon), Lyon, France

7. Department of Supportive Care, Curie Institute, Paris, France

8. Université Côte d'Azur, CHU Nice, LAMHESS, Plateforme Fragilité, Nice, France

9. INSERM UMR1231 CIC 1432, NACRe National Network, University of Burgundy FrancheComté, CHU Dijon, Dijon, France

10. University of Grenoble Alpes, INSERM, LBFA, Grenoble, France

11. Gastroenterology and Clinical Nutrition, $\mathrm{CHU}$ of Nice and University Côte d'Azur, Nice, France

12. Service d'Oncologie Radiothérapie, CHUTenon, IUC, AP-HP, Sorbonne Université, Paris, France

13. Department of Gastroenterology, University Hospital Pontchaillou, Rennes 1 University, INSERM U1242 "Chemistry Oncogenesis Stress Signaling", Rennes, France

14. Service d'Hépato-gastro-entérologie, CHUF. Mitterrand, Dijon, France

15. Department of Surgical Oncology, CHU Ambroise Paré, UVSQ - Paris Saclay University, Boulogne-Billancourt, France

16. Nutritional Assistance Department and Transversal Nutrition Unit, University Hospital of Nancy, University of Lorraine, Vandoeuvre-lès-Nancy, France

17. Département Interdisciplinaire d'Organisation des Parcours Patients (DIOPP), Gustave Roussy - CancerCampus, Villejuif, France

18. Department of Medical Oncology, Institut de Cancérologie de l'Ouest, Nantes, France

19. Department of DigestiveSurgery, Curie Institute, Paris, France

20. Department of Digestive Oncology, CHUReims, Reims, France 
21. Department of Gastroenterology, IBD and Nutrition Support, CHU Beaujon, AP-HP, Paris 7 Diderot University, Clichy La Garenne, France

Word count: 7,500.

Tables/Figures: 6/1.

Running Title: French clinical practice guidelines for nutrition and physical activity in digestive cancers

Key Words: Adapted Physical Activity; Chemotherapy; French Clinical Practice Guidelines; Radiotherapy; Surgery. 
Abbreviations

6MWT: 6-minute walk test

APA: adapted physical activity

BIA: bioimpedancemetry

BMI: body mass index

BP: blood pressure

CCLR: calorie-carbohydrate-lipid ratio

CRC: colorectal cancer

CRP: C-reactive protein

$\mathrm{CT}$ : computed tomography

DXA:X-ray absorptiometry

ECOG-PS: Eastern Cooperative Oncology Group Performance Status

ESPEN: European Society for Clinical Nutrition and Metabolism

ESTRO: European Radiotherapy Society

GPAC: Global Physical Activity Questionnaire

HR: Heart rate

HRQoL: health-related quality of life

IMA: indexed muscle area

IPAQ: International Physical Activity Questionnaire

L3: third lumbarvertebra

MNA: Mini Nutritional Assessment

MUST: Malnutrition Universal Screening Tool

NG: nutritional grade 
NICE: National Institute for Health and Care Excellence

NLR: neutrophil-to-lymphocyte ratio

NRS-2002: Nutritional Risk Screening-2002

ONS: oral nutritional supplements

PA: physical activity

PPI: proton pump inhibitor

PS: Performance status

SFNCM: Société Francophone Nutrition Clinique et Métabolisme

SNFGE: Société Nationale Française de Gastro-Entérologie

VAS: visual analog scale

VDS: verbal digital scale 


\section{ABSTRACT}

This document is a summary of the French Intergroup guidelines regarding the nutrition and physical activity (PA) management in digestive oncology. This collaborative work was produced under the auspices of all French medical and surgical societies involved in digestive oncology, nutrition, and supportive care. It is based on published guidelines, recent literature review and expert opinions. Recommendations are graded according to the level of evidence.

Malnutrition affects more than half of patients with digestive cancers and is often underdiagnosed. It has multiple negative consequences on survival, quality of life and risk of treatment complications. Consequently, in addition to anticancer treatments, supportive care including nutritional support and physical activity plays a central role in the management of digestive cancers. It is crucial to detect mal nutrition (diagnostic criteria updated in 2019) early, to prevent it and to act against it at all stages of the cancer and at all times of the care pathway. In this context, we proposed recommendations for the evaluation and management in nutrition and physical activity in digestive oncology for each stage of the disease (perioperative setting, during radiation therapy, during systemic treatments, at the palliative phase, after cancer).

Guidelines for nutrition and physical activity management aim at increasing awareness about malnutrition in oncology. They are continuously evolving and need to be regularly updated. 


\section{INTRODUCTION}

\subsection{Background}

Malnutrition is present in approximately $40 \%$ of cancer patients [Table 1] [1, 2] and is often underdiagnosed $[3,4]$. It is more frequent in older patients and in those with advanced disease $[2,5]$. In digestive oncology, its prevalence exceeds $60 \%$ in patients with pancreatic or esogastric cancer [1, 2].

Malnutrition is due to an imbalance between reduced energy and protein intake and increased expenditures [6]. In digestive cancers, malnutrition pathophysiology is multifactorial [Table 2].

Malnutrition has multiple negative consequences, including altered health-related quality of life (HRQoL), decreased survival, and increased risk of complications [7]. The nutritional status of the patient conditions her/his prognosis in the same way as the tumor stage [8]. Overall, malnutrition is responsible for a loss of opportunity for patients.

Malnutrition, sarcopenia and cachexia are three overlapping entities:

- malnutrition, not specific to oncology, is defined clinically by the association of at least: (i) one phenotypic criterion: weight loss, low body mass index (BMI), or reduction in mass and/or muscle function; (ii) and one etiological criterion: decreased food intake, reduced absorption, or aggression situations including cancer [9];

- sarcopenia was initially a geriatric concept to describe the age-related loss of strength and muscle mass, and has been transposed into oncology under the concept of secondary sarcopenia [7, 10,11]. It can be diagnosed by body composition analysis using X-ray absorptiometry (DXA), bioimpedancemetry (BIA), abdominal computed tomography (CT) scan slice at the level of the third lumbar vertebra (L3), and/or muscle strength or function assessments (e.g. handgrip strength test, sit to stand test, walking speed) [9];

- cachexia is defined by a loss of skeletal muscle with or without loss of fat mass secondary to hypercatabolism in an inflammatory setting [12]. Three stages are described: pre-cachexia, cachexia and refractory cachexia, the latter being non-reversible and justifying an earlymanagement for cancerrelated cachexia [13].

Consequently, in addition to conventional treatments, supportive care including nutritional support and physical activity (PA) plays a decisive role in the management of digestive cancers. It is crucial to detect malnutrition early, to prevent it and to act against it at all stages of the cancer and all times of the care pathway [3].

\subsection{Methods}

This guideline is a collaborative work under the auspices of all French medical and surgical societies involved in supportive care in digestive cancers. The primary aim was to develop recommendations 
using only methodologically established evidence-based guidelines or primary evidence, and to achieve an interdisciplinary consensus. A writing multidisciplinary committee gathering experts from different specialties involved in digestive oncology, nutrition, and supportive care (surgeons, radiation oncologists, medical oncologists, geriatricians, gastroenterologists, palliative care specialists, nutritionists, dietitians, physical activity professionals) was designated to review recent literature (PubMed search until January 2019 and international congress abstracts of randomized trials) and to write a first document after interactive discussions. This initial document was reviewed and modified after further evaluation by a review committee and the last version was finally validated by the steering committee of the participating National Societies. The present paper is a summary of the French intergroup guidelines published in June 2020 on the web site of the SNFGE (Société Nationale Française de Gastro-Entérologie) www.tncd.org. Recommendations based on this level of evidence were scored in three categories (grade A-C) according to the GRADE system [14, 15], with only expert opinion (agreement or not, grade D) when no scientific evidence was validated [Table 3]. All the statements in the present article completelymatch the original full guidelines, with no additional data or comments.

\section{EVALUATION OF NUTRITIONAL STATUS AND PHYSICALCONDITION}

\subsection{NUTRITIONAL STATUS: Clinical parameters}

\subsubsection{Weight loss}

Weight loss is a phenotypic diagnostic criteria for mal nutrition [9].

- Diagnostic threshold for malnutrition: weight loss $\geq 5 \%$ in one month or $\geq 10 \%$ in six months or $\geq 10 \%$ compared to the usual weight before the onset of the disease [9].

- Severe malnutrition threshold: weight loss $\geq 10 \%$ in one month or $\geq 15 \%$ in six months or $\geq$ $15 \%$ compared to the usual weight before the onset of the disease [9].

Weight measurement is not always reliable and can be overestimated in case of increase in extracellular hydration (oedema, ascites) [7].

\subsubsection{Bodymassindex (BMI)}

$\mathrm{BMI}$ is a phenotypic diagnostic criteria for mal nutrition [9].

- Diagnostic threshold for mal nutrition in adults: $\mathrm{BMI}<18.5 \mathrm{~kg} / \mathrm{m}^{2}$.

- Diagnosticthreshold for malnutrition in older adults ( $\geq 70$ years old): BMI $<21.0 \mathrm{~kg} / \mathrm{m}^{2}$.

- Severe malnutrition threshold: $\mathrm{BMI} \leq 17 \mathrm{~kg} / \mathrm{m}^{2}$ in adults and $\leq 18 \mathrm{~kg} / \mathrm{m}^{2}$ in older adults.

$\mathrm{BMI}$ can be overestimated in the event of oedema, ascites, or obesity.

\subsubsection{Anthropometry}

Anthropometry may be useful to complete the nutritional assessment; in particular, the measurement of the brachial muscular circumference can be used in the event of fluid retention (ascites, oedema of the lowerlimbs). 
In older patients, the measurement of arm and calf circumferences is included in the Mini Nutritional Assessment (MNA).

\subsubsection{Food intake}

Reduced food intake can precede weight loss.

Systematic evaluation of current dietary intake compared to usual intake (before cancer diagnosis) by a visual analog scale (VAS) or a verbal digital scale (VDS) (from 1 to 10 , threshold $\leq 7$ ) is easily feasible [16]. In addition, a three-day food survey can be carried out by a dietitian.

\subsection{NUTRITIONAL STATUS: Biological parameters}

\subsubsection{Albumin}

Albumin is a protein produced by the liver witha half-life of three weeks. Albuminemia can be lowered in the event of biological inflammatory syndrome (to be interpreted with C-reactive protein [CRP]), hepatocellular insufficiency, renal (nephrotic syndrome) or digestive (protein-losing enteropathy, iterative ascites punctures) losses. It is mainly a prognostic marker and not a reliable marker of mal nutrition. It is no longer used as a biological criterion for the diagnosis of malnutrition in adults [9]. In the presence of a clinically-defined malnutrition, al buminemia is a marker of severity:

- Moderate malnutrition threshold: albuminemia $<35 \mathrm{~g} / \mathrm{L}$

- Severe undernutrition threshold: albuminemia $\leq 30 \mathrm{~g} / \mathrm{L}$.

\subsubsection{Prealbumin}

Prealbumin (or transthyretin) has a half-life of three days. Faster to correct than albuminemia, it is useful for monitoring the effectiveness of nutritional interventions. It is no longer used as a biological criterion for the diagnosis of malnutrition nor for the evaluation of its severity [9].

\subsubsection{Inflammation}

The systemic inflammatory response promotes malnutrition by increasing catabolic activity and decreasing liver proteosynthesis. CRP (threshold $\geq 10 \mathrm{mg} / \mathrm{L}$ ), produced by the liver, is a specific marker of the systemic inflammatory response and predictor of morbidity and mortality, as well as the neutrophil-to-lymphocyte ratio (NLR). It is no longer used for the interpretation of albuminemia [9].

\subsubsection{Screening fordeficiencies}

- Systematic: ferritin, serum iron, transferrin saturation coefficient, blood ionogram, urea, creatinine, calcium, phosphorus, magnesium, prothrombin level;

- In case of malnutrition: vitamins B9, B12, D;

- In case of malabsorption or severe malnutrition, to be adapted according to the clinical evaluation: trace elements (copper, zinc, selenium), vitamins A, C, E, B1, B3 (formerly PP), B6.

\subsubsection{Clinical-biologicaltools/scales for malnutrition screening}


Numerous clinical-biological scores have been developed in order to screen for mal nutrition or predict complications.

These scales are not used in routine practice but in clinical trials. Malnutrition Universal Screening Tool (MUST) has been validated in a study as the best screening scale for malnutrition versus Nutritional Risk Screening-2002 (NRS-2002) according to the new definition of undernutrition by European Society for Clinical Nutrition and Metabolism (ESPEN) [17]. The MNA is of interest in patients aged $\geq 70$.

\subsection{NUTRITIONAL STATUS: Body composition}

\subsubsection{X-rayabsorptiometry (DXA)}

DXA uses a three-compartment model (fat mass, lean mass, and bone mineral content) to detect variations in lean mass, precisely and reproducibly. Thresholds for malnutrition were defined as appendicularmuscle mass $\leq 7.23 \mathrm{~kg} / \mathrm{m}^{2}$ in men and $5.67 \mathrm{~kg} / \mathrm{m}^{2}$ in women [9].

Limits of DXA include the lack of distinction between active cell mass and extra-cellular fluid (e.g. edema), and between the different types of adipose (visceral, subcutaneous, and intramuscular) and muscular (skeletal/striated and visceral/smooth) tissue [7].

\subsubsection{Bioimpedancemetry (BIA)}

$\mathrm{BIA}$ (single-frequency or multi-frequency) is a widespread non-invasive modality that uses reactance and resistance to determine the total amount of water in the body, body fat, and lean body mass. Thresholds for malnutrition were defined as muscle mass index $\leq 7.0 \mathrm{~kg} / \mathrm{m}^{2}$ in men and $\leq 5.7 \mathrm{~kg} / \mathrm{m}^{2}$ in women; non-fat mass index $<17 \mathrm{~kg} / \mathrm{m}^{2}$ in men and $<15 \mathrm{~kg} / \mathrm{m}^{2}$ in women [9].

BIA depends strongly on the hydration state of the patient and is biased in case of extra-cellular hyperhydration. Other limits include the lack of standardization and specific predictive equations for older patients, extreme BMI, and cancer patients, which can lead to inaccuracies and heterogeneity in the prevalence rates of sarcopenia [7].

\subsubsection{AbdominalCTscan using the $L 3$ section}

The skeletal muscle area evaluated on a cross section at the level of L3 by CT-scan (or magnetic resonance imaging) reflects the total skeletal muscle mass $[18,19]$. The indexed muscle area (IMA) is measured manually or using semi-automatic segmentation software then normalized according to the size squared to obtain an index in $\mathrm{cm}^{2} / \mathrm{m}^{2}$. Thresholds for malnutrition were defined as IMA $\leq 52.4$ $\mathrm{cm}^{2} / \mathrm{m}^{2}$ in men and $38.5 \mathrm{~cm}^{2} / \mathrm{m}^{2}$ in women [9].

Limits of CT scan include the lack of consensus on the technical aspects for measuring the skeletal muscle surface and thresholds for cancer patients $[4,18]$. Other simplified methods (e.g. surface or density of the psoas) are not validated [7].

\subsection{PHYSICAL CONDITION: Anamnesis}


Physical fitness is made up of cardio-respiratory (aerobic) capacity, muscle strength, muscular endurance, flexibility, balance, and body composition. The decrease in PA level and the increase in sedentary behavior contribute to the loss of physical fitness and to the accelerated deterioration of the general status in cancer patients.

The objective of anamnesis is to evaluate the PA level and identify clinical elements that may impact the practice of PA.

\subsubsection{Performancestatus(PS)}

PS reflects PA level and therefore exercise tolerance (aerobic capacity) [20]. It is assessed by the Eastern Cooperative Oncology Group (ECOG-PS) scale or Karnofsky's index [21].

\subsubsection{History of the disease and symptoms}

- Comorbidities: heart failure, respiratory failure, osteoarticular disorders, obesity, neurological and psychiatric disorders, other pathologies causing functional limitation.

Note: cardiac (e.g. coronary artery disease), pulmonary (e.g. chronic obstructive pulmonary disease) or osteoarticular (e.g. low back pain, arthritis) history does not contra-indicate the practice of an adapted and individualized PA, and can on the contrary benefit from it.

- Symptomatic tumor locations: peritoneal carcinomatosis, bone metastases, painful hepatomegaly.

Note: bone metastases, except lytic lesions at risk of fracture complications, are not contraindications to the practice of an adapted and individualized PA.

- Thromboembolic complications: deep vein thrombosis of the lower limbs, pulmonary embolism.

Note: in the absence of signs of gravity and after anticoagulation for at least seven days, they are not contraindications to the practice of an adapted and individualized PA.

- Side effects of treatments: sequelae of surgery, neuropathy, hand-foot syndrome, anemia.

- Polymedication, especially in the older patients.

\subsubsection{Fatigue}

Evaluation of fatigue using a VAS is feasible in daily practice: moderate fatigue threshold $\geq 4$, severe fatigue threshold $\geq 7$ [22]. Questionnaires can be used in clinical trials.

\subsubsection{Pain}

Evaluation of pain using a VAS is feasible in daily practice: moderate pain threshold $\geq 4$, severe pain threshold $\geq 7$. Questionnaires can be used in clinical trials.

\subsubsection{Physicalactivity habits and level}

It consists in the evaluation of usual (before diagnosis) and current level of sedentary and PA behaviors in professional, domestic, travel, leisure and sports activities: 
- PA intensities can be assessed by a shortness of breath index (none, moderate, severe) and/or a VAS or VDS of perception of effort (e.g. modified Borg scale from 1 to 10);

- Identify the time spent per week in moderate to vigorous PA, i.e. effort made at least at the limit of shortness of breath and/or VAS effort $\geq 2$;

- Questionnaires can be used in clinical trials or clinical practice: short International Physical Activity Questionnaire (IPAQ), Global Physical Activity Questionnaire (GPAQ).

It also includes questions about patient's preferences/interests/motivations as well as barriers to practice:

- Physical barriers: feeling of persistent fatigue, pain, feeling of being weakened and lacking in capacity;

- Psychological barriers: body dissatisfaction, lack of motivation, perception of a lack of competence, fear of injury or worsening of health status, previous negative experiences;

- Environmental and economic barriers: lack of time, scarce financial resources, limited access to places of practice and PA professionals, unfavorable family, cultural and/or social environment.

\subsection{PHYSICAL FITNESS TESTS}

Physical fitness must be assessed initially and reassessed regularly. These assessments are most often carried out by physiotherapists or professionals in Adapted Physical Activity (APA) in order to adapt and individualize the PA program and to assess changes in physical fitness. Body composition is also part of the physical fitness assessment (see 2.3.).

\subsubsection{Muscularstrength}

Upper limbs strength can be assessed by the handgrip test using a dynamometer [23-25]; thresholds for malnutrition were defined as strength $<26 \mathrm{~kg}$ in men and $<16 \mathrm{~kg}$ in women [9]. Lower limbs strength can be assessed by the sit to stand test.

\subsubsection{Aerobic capacity and exercise tolerance}

Heart rate (HR) and blood pressure (BP) should be measured after 5 minutes of extended rest. Aerobic capacity can be assessed by the 6-minute walk test (6MWT): distance walked and observation of walking disorders; speed monitoring over the course of six minutes makes it possible to assess fatigability, either every 30 seconds (distance walked) or at each round trip (time taken). The threshold for malnutrition is defined as walking speed $<0.8$ meter per second [9].

\subsubsection{Dynamicand static balance tests}

They are of particular interest in older patients with risk of falls and in case of neuropathy. They include the timed get up and go test and single leg stance test. 


\subsection{Recommendations and options}

\subsubsection{RECOMMENDATIONS}

- Screening for mal nutrition and assessment of its severity, for all patients, regardless of the location of the cancer and its stage, at diagnosis and then regularly during follow-up: collect the following parameters in the patient record (expert agreement):

- Clinical (for diagnosis and interpretation of measurements): age, current weight (at least once a week in hospital, once a week at home and at each consultation during treatment, at least once a month at home and at each consultation during post-treatment follow-up), weight one month ago, six months ago and usual weight (before diagnosis), weight loss (\%), height, BMl, presence of ascites and/or edema, VAS of food intake (threshold $\leq 7$ );

- Biological (for severityand the search for deficiencies): at least once a month during treatment and at least once every three to six months during post-treatment follow-up: blood cell count (including NLR), albumin (for severity of malnutrition), pre-albumin (for monitoring of nutritional interventions), CRP, blood ionogram, urea, creatinine, calcium, phosphorus, magnesium, prothrombin level; once every three to six months: ferritin, serum iron, transferrin saturation coefficient.

- Assessment of physical condition (expert agreement):

- Clinical: PS and VAS of fatigue (threshold $\geq 4$ ) at diagnosis then at each consultation; PA level, resting $\mathrm{HR}$ and $\mathrm{BP}$ at diagnosis and then every three to six months;

- Elements that can impact the practice of PA: symptomatic tumor locations, comorbidities, polymedication, motivation, fatigue, pain, psychosocial environment.

\subsubsection{OPTIONS}

- In case of malnutrition and during follow-up: dosage of vitamins B9, B12, D can be carried out every two to three months (expert opinion);

- In case of long-term artificial nutrition (>three months): micronutrient dosages can be performed every three to six months \pm trace elements (copper, zinc, selenium), vitamins A, C, E, B1, B3, B6 (expert opinion);

- Sarcopenia on CT scan (expert agreement);

- Measurement of the brachial muscle circumference if ascites or edema of the lower limbs (expert opinion);

- MNA score if $>70$ years (expert agreement);

- MUST score (expertopinion);

- Fitness tests: handgrip test, sit to stand test, walking speed, 6MWT, timed get up and go test and single leg stance test (older patients/neuropathy) (expertagreement). 


\subsection{Special situations}

\subsubsection{Severe malnutrition and refeeding syndrome}

A major issue in the nutritional care of patients experiencing aggression is the prevention of refeeding syndrome which can lead, in the absence of treatment, to multiple organ failure.

Very severely malnourished patients (National Institute for Health and Care Excellence [NICE] criteria, Table 4) are at high risk of developing refeeding syndrome during their nutritional management [26]. If there is a risk of refeeding syndrome, the serious clinical consequences must be prevented by:

- immediate correction of hydroelectrolytic disorders observed before the start of refeeding (hypokalaemia, hypophosphoremia);

- a systematicintake of vitamin B1 before refeeding;

- a gradual increase in energy intake with an adequate supply of micronutrients;

- clinical and biological monitoring during the first days to assess signs of complications (e.g. hypophosphoremia, edema) [26].

\subsubsection{Older patients}

The risk of malnutrition is increased in older patients ( $\geq 70$ years) with digestive cancers [27]. It is recommended that the nutritional care plan be integrated into a global geriatric care plan [28]. The intervention of an oncogeriatrician is useful and recommended if the G8 score is $\leq 14$ [29].

The evaluation of the nutritional status in older patients with cancer is similar to that of an elderly subject without cancer and that of the younger subject, by adding the MNA and taking into account different thresholds as mentioned above. Weight loss should be avoided during and after treatments, even in overweight patients. For PA management, it is necessary to consider possible balance disorders and the risk of falls.

\subsubsection{Obese patients and obesity-related cancers}

Overweight $\left(\mathrm{BMI} \geq 25 \mathrm{~kg} / \mathrm{m}^{2}\right)$ and obesity $\left(\mathrm{BMI} \geq 30 \mathrm{~kg} / \mathrm{m}^{2}\right)$ are risk factors for morbidity and mortality, especially through cardiovascular diseases and cancers, including gallbladder cancer, hepatocellular carcinoma, adenocarcinoma of the pancreas, esophagus, cardia, and colorectal cancer (CRC) [30, 31]. In patients with digestive cancers, overweight and/or obesity is deleterious or beneficial depending on the tumor location [32-34].

Obese patients may be malnourished; there is a risk of ignoring sarcopenic obesity if only weight or $\mathrm{BMI}$ are considered; body composition analysis tools (e.g. CT scan) are particularly useful in this situation.

Nutritional and PA interventions before surgery and during the active phase of treatments must aim for weight stabilization and preservation of lean mass and not rapid weight loss during this period, since it would affect muscle mass more than fat mass and expose at an increased risk of complications and toxicities [35]. 
In patients with CRC, a high BMI is associated with an increased risk of second cancer linked to overweight/obesity [36]. In these patients, it is recommended in tertiary prevention to reduce BMI after the active treatment phase while preventing, detecting and if necessary treating malnutrition.

\subsubsection{Perioperative setting}

Before any scheduled cancer surgery, it is essential to identify patients at risk of mal nutrition in order to improve the prognosis and post-operative consequences [37].

Perioperative nutritional management is based on nutritional grade (NG, Table 5). With a few exceptions (e.g. simple colostomy), oncological digestive surgery is considered to be at high risk of morbidity, and patients are classified as NG2 if not malnourished or NG4 if malnourished.

\section{PERIOPERATIVE SETTING}

\subsection{Nutrition in in the perioperative setting}

\subsubsection{Literature data}

In patients scheduled for digestive surgery for digestive cancer, malnutrition is frequent ( $20 \%$ to $50 \%$ ) and is associated with an increase in morbidity (in particular, anastomotic and infectious complications), mortality and length of hospital stay [38]. The perioperative nutritional management strategy must be defined as soon as the consultation with the surgeon or anesthesiologist [Table 6] [37, 39]. The recommended intakes are 25 to $30 \mathrm{kcal} / \mathrm{kg}$ per day, including 1.2 to $1.5 \mathrm{~g}$ of protein $/ \mathrm{kg}$ with a calorie-carbohydrate-lipid ratio (CCLR) of about 60/40 [40].

Immunonutrition or pharmaconutrition aims to promote healing, reduce the risk of post-operative infectious complications and the length of stay [40]. It consists of an enriched supply of proteins, associated with arginine, glutamine, micronutrients, omega-3 polyunsaturated fatty acids, and bacterial nucleotides. These supplements are packaged in vials of $250 \mathrm{~mL}$ for oral route (Oral Impact ${ }^{\circledR}$ ) and enteral route $\left(\right.$ Impact ${ }^{\circledR}$ Entéral).

Early oral feeding should be encouraged, in most cases starting on the day of surgery after agreement of the surgeon. This does not increase the risk of fistula and shortens the length of hospital stay, mortality, and the resumption of bowel activity [40]. Nutritional support must be introduced if it is foreseeable that oral feeding will not be resumed before the fifth post-operative day or that the patient will ingest less than $60 \%$ of her/his caloric needs in the first seven post-operative days [40].

The enteral route should be preferred because it reduces the number of infectious complications, the length of stay and the hospital costs compared to parenteral nutrition [41, 42]. Adding parenteral nutrition should be considered if the oral and enteral intake is insufficient to cover at least $60 \%$ of caloric needs or if there is a contraindication to enteral nutrition [40].

\subsubsection{Recommendations and options}

RECOMMENDATIONS 
- Recommended intakes of 25 to $30 \mathrm{kcal} / \mathrm{kg}$ per day including 1.2 to $1.5 \mathrm{~g}$ of protein per $\mathrm{kg}$ (expert agreement).

- Non-malnourished patient (NG2) (expert agreement):

- $\quad$ Oral Impact ${ }^{\circledR}$ three vials/day for five to seven days before surgery;

- Limited pre-operative fasting (< two to three hours for "clear" liquids and six hours for a light meal) and early post-operative oral feeding;

- No post-operative nutritional support unless predictable or measured intakes $<60 \%$ of needs on day 7.

- Malnourished patient (NG4) (expert agreement):

- Oral or Enteral Impact ${ }^{\circledR}$ pre-operative (three vials/day or $1000 \mathrm{~mL} /$ day for five to seven days) and post-operative (four to five vials/day or $1500 \mathrm{~mL} /$ day for at least seven days);

- Complete with nutritional support (prefer enteral rather than parenteral route) for seven to 14 days pre-operatively and continued post-operatively;

- Limited pre-operative fasting and early post-operative oral feeding;

- Beware of the risk of refeeding syndrome.

\subsubsection{Special situations}

- Emergency surgery:

- Nutritional assessment before the intervention if possible, otherwise within 48 hours postoperatively;

- Management is similar to scheduled surgery; in practice, after emergency surgery, oral refeeding (oral route or catheter) can only rarely be resumed within 24 hours post-operative due to the reflexileus, with gastrictube often productive;

- If the patient is septic: supplement containing arginine (Oral Impact ${ }^{\circledR}$ and Impact $^{\circledR}$ Enteral) should not be used.

- Obese patients:

- Overweight, obesity, and sarcopenic obesity are associated with an increased risk of postoperative morbidity and mortality and prolonged hospital stays;

- The risk of mineral and micronutrient deficiency is greater than in the normal weight subject. Screening for iron deficiency and correcting the deficit are recommended. In case of weight loss (in particular, in case of previous bariatric surgery), a pre-therapeutic nutritional assessment is recommended in order to look for hypoalbuminemia and specific deficiencies (vitamins, trace elements);

- Restrictive diets leading to a significant loss of lean mass are not recommended.

- Diabetic patients:

- Diabetes can increase the risk of malnutrition and micronutrient deficiency; 
- There is a potentiation of the risk of post-operative complications in diabetic and malnourished patients;

- Avoid restrictive diets; adjust the anti-diabetic treatment to the protein-energy intake of the patient; practicing PA can also help regulate blood sugar;

- Patients can receive usual oral nutritional supplements (ONS) in first intent and if the blood sugar level is difficult to control then use specific ONS for diabetics (lower glycemic index) [43]

- Gastroparesis is more frequent postoperatively in diabetic patients, but should not be an obstacle to enteral nutrition (prokinetics, post-pyloric tube);

- There is a risk of glycemic imbalance with parenteral nutrition: favor enteral nutrition and initiate/increase insulin therapy in the case of parenteral nutrition.

\subsection{Physical activity in the perioperative setting}

\subsubsection{Literature data}

Any nutritional intervention must be coupled with PA, including perioperatively $[40,44]$.

- Pre-operative setting:

- The patient's physical fitness is impacted by the cancer and co-existing diseases (e.g. cardiovascular or pulmonary disease). Patients with poor physical fitness have higher postoperative morbidity and mortality [45].

- Studies with small sample size are in favor of multimodal prehabilitation programs (nutrition, diabetes/hypertension control, smoking/alcohol cessation, psychological/stress management, aerobic and resistance structured exercises) in abdominal surgery with a benefit on aerobic capacity in randomized controlled studies and reduction in the risk of postoperative complications in one of them [46-50].

- The implementation of pre-operative PA program is not always feasible for digestive cancers operated without neoadjuvant treatment (delay before surgery of less than one month). However, in these patients, information about PA from the start of treatment is essential so that they do not lower their PA level and maintain their physical fitness.

- In those operated after neoadjuvant chemo(radio)therapy (delay of two to three months), it is easier to consider PA programs [51]. Here too, information about PA is important and referral to an APA professional is possible, in particular for patients with barriers to the implementation of PA.

- Post-operative setting:

- Post-operative fatigue (intense fatigue, poor concentration, poor exercise tolerance) is frequent and can have an impact on HRQoL. It can last several weeks after abdominal surgery. 
- Post-operative fatigue has a multifactorial etiology (including the production of proinflammatory cytokines, loss of weight and muscle mass, decreased food intake, anxiety and depression) and requires multimodal intervention.

- The practice of APA after surgical resection of a tumor has been shown to be safe [52]. A structured early mobilization plan should set up with realistic dailyobjectives, from the day of the intervention, with the surgeon's agreement.

\subsubsection{Recommendations and options}

\section{RECOMMENDATIONS}

- Education and information of the patient about the benefits of PA (reduction of fatigue and the risk of post-operative complications), from the consultation for disease announcement (expert agreement).

- Early post-operative mobilization by a physiotherapist (expert agreement).

- Limit sedentary behaviors (sitting or bedtime) and encourage regular PA (progressive implementation and taking into account postoperative limitations), by combining aerobic and resistance exercises, before and after surgery (expert agreement).

\section{OPTIONS}

- Pre-operative multimodal prehabilitation: structured aerobic and resistance exercises associated with nutrition, diabetes/hypertension control, smoking/alcohol cessation, psychological care/stress (expertopinion).

- Pre-operative respiratory rehabilitation (physiotherapy and PA) for surgeries with thoracic approach (expertagreement).

- Post-operative respiratory physiotherapy if necessary for all tumor locations (expert agreement).

- Refer to an APA professional, in particular for patients with barriers to practice: comorbidities, intense fatigue and/or significant and recent drop in the PA level, negative beliefs and fears about PA (expertopinion).

\subsubsection{Special situations}

- PA is contra-indicated in the following cases: extreme fatigue, symptomatic anemia, severe active infectious syndrome, decompensation of cardiopulmonary disease, lytic bone lesions of the spine or long bones (for the mobilization of the affected limb). The majority of these situations are temporary. The patient's condition should be reassessed regularly so as not to slow down their commitment to an active lifestyle and avoid excessive loss of physical fitness.

- An adaptation of the APA prescription will be necessary in the following cases: cardiopulmonary comorbidities, osteoporosis with high risk of fractures, significant amyotrophy, peripheral neuropathy, impaired mobility and stability of the joints, lymphedema, recent abdominal scar, digestive or urinary stomas. 
- Other elements require special precautions:

- Co-morbidities: to be considered in the APA program; must be detailed to the professional supervising the sessions for safe support;

- Early post-operative setting of abdominal surgery: avoid concentric exercises (resistance exercises in flexion/rotation of the trunk) stressing the muscles of the abdominal wall after laparotomy;

- Thoracotomy: avoid exercises in Valsalva maneuver and stretching of the trunk in early postoperative setting; take into account the increase in bronchial secretions induced by exercise (adapt duration, allow break time to allow sputum);

- Anal incontinence (post-surgery and/or radiotherapy): avoid activities with impact on the ground or in Valsalva maneuver and promote resistance exercises of the perineal muscles;

- Radiodermitis: precaution with aquatic activities (standing water to be avoided);

- Ostomy: avoid concentric exercises involving the muscles of the abdominal wall in the early post-operative period after laparotomy; avoid activities at risk of shock to the stoma; possible use of suitable equipment (plugs); adapt the duration and the time of the activity to the flow of the stoma.

\section{DURING (CHEMO)RADIOTHERAPY}

\subsection{Nutrition and radiotherapy of digestive cancers}

\subsubsection{Literature data}

No specific data or recommendations are available from the European Radiotherapy Society (ESTRO) or ESPEN. The risks of malnutrition mainly concern patients with cancers of the upper aerodigestive tract or, much less frequently, pelvic cancers.

- In the case of digestive cancer treated by curative chemoradiotherapy, the irradiation volume of which includes the oropharynx and the oral cavity:

- In non-malnourished patient: propose prophylactic gastrostomy placement;

- In malnourished patient: gastrostomy is recommended;

- In all cases, parenteral nutrition is not recommended.

- In the case of digestive cancer treated with chemoradiotherapy for curative purposes, the irradiation volume of which does not include the oropharyngeal sphere:

- Prophylactic gastrostomy is not recommended;

- Personalized dietary advice including, if necessary, the prescription for ONS is recommended as a first intention;

- Enteral nutrition on a nasogastric tube is recommendedif oral intake remains insufficient (VAS $\leq 7)$. 
- In case of planned surgery: nasogastric tube or jejunostomy is recommended; endoscopic or radiological gastrostomy is also an alternative and does not increase post-operative morbidity and mortality but it must be inserted by trained teams, on the anterior wall of the stomach and as close as possible to the lesser curvature, so as not to compromise the subsequent surgery; do not use esophageal stent [53].

\subsubsection{Recommendations and options}

\section{RECOMMENDATIONS}

- None

OPTIONS

- Cancers of the esophagus (upper third and middle third) (expert opinion):

- Systematic ONS;

- Endoscopic or radiological gastrostomy (rather than nasogastric tube for enteral feeding) during chemoradiotherapy if exclusive chemoradiotherapy (no surgery);

- In case of planned surgery: nasogastric tube or jejunostomy; endoscopic or radiological gastrostomy on the anterior wall of the stomach by trained teams is an al ternative; do not use esophageal stent;

- Parenteral nutrition not recommended.

- Cancers of the lower third of the esophagus (expertopinion):

- Systematic ONS;

- Nasogastric tube or jejunostomy, or gastrostomy with the precautions mentioned above;

- Parenteral nutrition not recommended.

- Pancreatic cancer: ONS \pm enteral nutrition (nasogastric tube) if malnutrition (expertopinion).

- Cancers of the rectum/anal canal: ONS \pm enteral nutrition (nasogastrictube) if malnutrition (expert opinion).

\subsection{Physical activity and radiotherapy of digestive cancers}

4.2.1. Literature data

No specific recommendations from ESTRO. No specific recommendation from ESPEN; any nutritional intervention must be coupled with PA, including during radiotherapy.

The objective, during treatments, is to prevent or limit the reduction in PA level, from the start of treatment [44]. To do this, it will be necessary to:

- Limit the time of sedentary behavior, to break the prolonged periods spent in lying or sitting position;

- Allow a return to active behavior as soon as possible;

- Maintain or promote an active lifestyle during radiotherapy and medical treatment. 


\subsubsection{Recommendations and options}

\section{RECOMMENDATIONS}

- Education and information of the patient about the benefits of PA during treatment (reduction of fatigue and increase of physical fitness), from the consultation for disease announcement (expert agreement).

- Limit sedentary behavior (sitting or bedtime) and encourage regular PA (progressive implementation and taking into account the side effects and constraints of radiotherapy), combining aerobic and resistance exercises (expert agreement).

OPTIONS

- Refer to an APA professional, in particular for patients with barriers to PA: comorbidities, intense fatigue and/or significant and recent drop in the PA level, negative beliefs and fears about PA (expert opinion).

\section{DURING SYSTEMIC TREATMENTS [Figure 1]}

\subsection{Nutrition during systemic treatments}

\subsubsection{Literature data}

There is a consensus to $[3,39,54]$ :

- Evaluate the nutritional status (screening for malnutrition) of all patients and reassess it regularly;

- Implementsuitable nutritional interventions (dietary counselling, ONS, enteral and parenteral feeding) according to oral intake (VAS of food intake), inflammatory syndrome and PA level;

- The recommended intakes are 30 to $35 \mathrm{kcal} / \mathrm{kg}$ per day including 1.2 to $1.5 \mathrm{~g}$ of protein $/ \mathrm{kg}$ with a calorie-carbohydrate-lipid ratio of about 60/40;

- Except in the case of an unusable or inaccessible digestive tract (e.g. bowel obstruction), enteral nutrition is to be preferred over parenteral nutrition.

In the event of advanced disease with upper digestive stenosis (esophagus, stomach, pancreas): stenting by endoscopic route is recommended in first intention (rather than surgery or gastrostomy) [53].

Therapeutic fasting and restrictive diets (e.g. sugar exclusion, ketogenic diet) have not demonstrated clinical benefit and can have a deleterious effect on the nutritional status of patients; they are therefore not recommended [55].

The level of evidence regarding the use of pharmacological agents (e.g. progestins, olanzapine, androgen receptor agonists, ghrelin analogues, corticosteroids, L-carnitine) or enriched ONS (e.g. leucine, glutamine, $n-3$ fatty acid) is insufficient.

\subsubsection{Recommendations and options}




\section{RECOMMENDATIONS}

- Evaluate the nutritional status (screening for mal nutrition) of all patients and reassess it regularly at each consultation (expertagreement).

- Recommended intakes of 30 to $35 \mathrm{kcal} / \mathrm{kg}$ per day including 1.2 to $1.5 \mathrm{~g}$ of protein per $\mathrm{kg}$ (expert agreement).

- Implement nutritional interventions (dietary counselling, ONS, enteral and parenteral feeding) according to oral intake (VAS of food intake), inflammatory syndrome and PA level (expert agreement).

- Enteral nutrition is indicated if the oral intake (including ONS) is insufficient, and parenteral nutrition if the enteral is impossible or insufficient (expert agreement).

- The recommendations of the SFNCMare presented in Figure 1.

\subsubsection{Special situations}

- Very severely malnourished patients (refer to NICE criteria above): specific management by an expert team is recommended because of the risk of refeeding syndrome, including the monitoring of potassium, phosphorus, sodium, magnesium, and calcium levels, edema, vitamin deficiencies [26].

- Sequelae of treatments: parenteral nutrition is recommended in cases of intestinal insufficiency linked to short bowel syndrome or enteritis secondary to surgery or radiotherapy; follow-up in an expert center is recommended for patients receiving long-term parenteral nutrition (>three months) [56].

- Ascites and peritoneal carcinomatosis

- Enteral nutrition is impossible in case of bowel obstruction;

- In the absence of bowel obstruction: assess the tolerance of enteral nutrition and if failure, use parenteral nutrition with careful initiation due to the risk of worsening of ascites;

- In case of chylous ascites: low fat diet, enteral nutrition poor in long-chain triglycerides, and if failure parenteral nutrition with usual ternary mixture.

- Pancreatic cancer

- In case of signs of exocrine pancreatic insufficiency (diarrhea with fatty stools, fecal elastase< 100 microgram/gram of stool): prescription of pancreatic extracts (at least 25,000 IU per meal; possibility of combined prescription with proton pump inhibitor [PPI] to increase efficiency);

Glycemic monitoring and treatment of a possible diabetes: metformin in first intention \pm insulin.

- Toxicities from chemotherapy: prevention and treatment of mucositis, nausea/vomiting, diarrhea.

\subsection{Physical activity during systemic treatments}

\subsubsection{Literature data}


During chemotherapy, PA can be effective to reduce fatigue and other symptoms, as well as the side effects of treatments [44]. A benefit on anxiety, depression, sleep, body image and well-being have also been reported, resulting overall in an improvement in patients' HRQoL [57-59]. Exercise could also have antitumor effects [60,61].

Fatigue in cancer patients is multifactorial, involving the disease itself, treatments, sedentary behaviors and the decrease in PA level leading to a loss of physical fitness [22]. The practice of PA is the only intervention having proven its efficacy on cancer-related fatigue, while pharmacological agents did not show any significant effect on this symptom [62].

Small randomized studies have been performed in patients with CRC [63]. While they did not allow a definitive conclusion on the efficacy of PA, they did, however, confirm the feasibility and safety of these interventions [63]. Larger prospective randomized controlled trials with a rigorous methodology are necessary in order to better understand the effects of PA (e.g. NCT00819208), identify the patients who benefit from it the most, describe the barriers and facilitators to these interventions and understand the mechanisms of action (ancillary studies) during active treatments in digestive oncology.

There is no data to favor one modality of exercise over another, but supervision by an APA professional seems to be important to maintain the motivation and encourage the autonomy of the patient in PA practice.

The objective, during the treatments, is to prevent the reduction of PA level, from the start of the therapeutic management, by:

- Reducing the daily sedentary behavior time and break the prolonged periods of sedentary behavior by short activity phases of a few minutes every two hours;

- Promoting an active lifestyle with spontaneous daily PA;

- Offering aerobic and resistance exercises, voluntary and at least partially supervised by an APA professional. The APA program (frequency, intensity, duration and type of exercise) will be individualized depending on the initial assessment of the patient, her/his physical fitness, preferences and objectives, illness, and psychosocial environment. The exercises will be implemented gradually and regularly reassessed and readjusted in coordination with the multidisciplinary oncology team. Physical exercises can be carried out individually or groupbased, in a care structure, an association (specific to cancer or not) or at home;

- Providing motivational and educational support throughout the care process to maintain PA and therefore its benefits over time: encourage facilitators (knowledge of the benefits of PA, conditions for correct exercise, support from family and/or group-based practice, access to structures for APA practice) and removing the barriers (treating symptoms related to the 
disease and treatments, psychosocial environment, beliefs and fears of the patient and caregivers) in daily PA practice;

- For older patients, integrating balance exercises (prevention of the risk of falling and loss of autonomy) into the APA program.

\subsubsection{Recommendations and options}

\section{RECOMMENDATIONS}

- Patient education and information on the benefits of PA during and after treatments (reduction of fatigue, improvement of HRQoL, and of physical fitness, potential effect on survival), from the consultation for disease announcement (expert agreement).

- Limit sedentary behaviors (sitting or bedtime) and encourage regular PA (progressive implementation and taking into account the side effects of treatments), at least partially supervised, combining aerobic and resistance exercises (expert agreement).

- Refer whenever possible to an APA professional for supervision, in particular for patients with barriers to PA or at risk: sarcopenia, comorbidities, metastatic disease, intense fatigue and or significant and recent drop in PA level, negative beliefs and fears about PA (expertagreement).

\subsubsection{Special situations}

- Comorbidities: to be considered in the APA program; must be detailed to the professional supervising the sessions for safe support.

- Implantable chamber: no activity while infusion is ongoing; avoid activities at risk of shock on the device.

- Picc-Line: avoid activities at risk of shock or friction on the device; no aquatic activities.

- Peritoneal carcinomatosis: avoid Valsalva maneuvering activities, activities at risk of shock and prone position.

- Bone metastases: avoid activities at risk of shock and with impacts on the ground, depending on the location of the metastaticlesion.

- Thromboembolic events: special attention to tolerance/perception of effort in aerobic activities (intensity control); avoid activities at risk of shock with anticoagulants.

- Toxicities of treatments:

- Nausea and fatigue are improved by the practice of individualized PA;

- Diarrhea must be treated with anti-diarrheal drugs;

- Neuropathy with oxaliplatin and taxanes: may cause balance and gait disturbances and interfere with activities (e.g. wear gloves for outdoor activities with oxaliplatin);

- Hand-foot syndrome with 5 fluorouracil, capecitabine and anti-angiogenic kinase inhibitors and skin lesions with anti-EGFR: may interfere with activities, suitable footwear, avoid impact on the ground if active events; 
- Increased photosensitivity: sunscreen and hat for outdoor activities;

- Cardiotoxicity with anti-HER2: cardiac monitoring, special attention to tolerance/perception of effort in aerobic activities.

\section{ADVANCED PALLIATIVE PHASE}

\subsection{Nutrition in the advanced palliative phase}

\subsubsection{Literature data}

The initiation of artificial nutrition is not recommended if the patient's life expectancy is less than three months and if the permanent functional impairment is severe (ECOG-PS $\geq 3$ or Karnofsky index $\leq 50 \%$ ), due to an unfavorable risk/benefit balance in this context [64].

The pursuit of artificial nutrition must be discussed in a multidisciplinary manner.

The decision must be recorded in the patient's file. A 15-day re-evaluation is recommended.

\subsubsection{Recommendations and options}

\section{RECOMMENDATIONS}

- Do not initiate artificial nutrition if life expectancy is less than three months (expert agreement).

\section{OPTIONS}

- Dietary advice \pm ONS (expertopinion).

- The initiation of artificial nutrition if life expectancy is less than three months must be carefully considered on a case by case basis taking into account all the elements of the context of each patient (age, life comfort, personal wishes), favoring enteral nutrition and using parenteral nutrition onlyif the digestive tract is unusable or inaccessible (expert opinion).

- Discussion on a case by case basis of the continuation of artificial nutrition if it was initiated before the cessation of specific treatments (expertopinion).

- Artificial nutrition must be discussed in a multi disciplinary committee and traced in the patient's file (expertagreement).

\subsection{Physical activity in the advanced palliative phase}

\subsubsection{Literature data}

There is no data of high level of evidence available. Comfort and well-being should be favored. Physiotherapists play an important role in this setting by mobilization, avoiding complications of bed rest, and lymphatic drainage (edema).

\subsubsection{Recommendations and options}

\section{RECOMMENDATIONS}

- None.

OPTIONS 
- Physiotherapy to avoid complications from bed rest and uncomfortable symptoms (expert opinion).

- APA with well-being objective (expert opinion).

\section{AFTER TREATMENT OF A DIGESTIVE CANCER}

\subsection{Nutrition after treatments}

\subsubsection{Literature data}

There are no specific data or recommendations. The World Cancer Research fund (WCRF) 2018 reports proposes to apply primary prevention guidelines in tertiary prevention.

Digestive cancer surgery can be responsible for a number of metabolic and functional side effects. They must be detected and managed quickly to improve HRQoL and avoid long-term complications.

\subsubsection{Recommendations and options} RECOMMENDATIONS

- None.

OPTIONS

- After esophageal and gastric surgery: regular weight monitoring (particularly in the first six months after surgery), monitoring for deficiencies (vitamins B9, B12, iron, vitamin D and calcium), referral to a dietitian if necessary, fractional feeding (five small meals) (expert agreement).

- After pancreatic surgery: same recommendations plus prescription of pancreatic extracts (at least 50,000 IU per meal; more particularly after pancreaticoduodenectomy) and glycemic monitoring (risk of diabetes, more particularly after splenopancreatectomy) (expert agreement); PPI after cephalic duodenopancreatectomy (expertopinion).

- After ileal resection: prescription of cholestyramine in case of diarrhea due to lack of reabsorption of biliary salts, monitoring of deficiencies (vitamins B9, B12, vitamin D and calcium) (expert agreement).

- After surgery for cancer linked to overweight and obesity (e.g. CRC): encourage a decrease in BMI after the end of treatment while preventing, detecting and if necessary treating malnutrition (expert opinion).

\subsection{Physical activity after treatments}

\subsubsection{Literature data}

In observational studies, the practice of PA before or/and after the diagnosis of cancer (particularly, (RC) is associated with better overall and specific survival compared to inactive patients $[63,65,66]$. The objective is the adoption and maintenance of an active lifestyle, which is bas ed on changes in life behavior and relies on the association of aerobic and resistance exercises [44]. 
The practice benchmarks join those defined for the general population (ANSES 2016) and those formulated by the main international learned societies for cancer patients (National Comprehensive Cancer Network, American Cancer Society, American College of Sports Medicine):

- Reduce the daily sedentary behavior time and break the prolonged periods of sedentary behavior by short activity phases of a few minutes every two hours;

- At least 30 minutes of aerobic PA per day of moderate to vigorous intensity, at least five days per week. It is recommended to include short periods of vigorous intensity aerobic PA. The duration and intensity of PA should be gradually increased and adapted to individual characteristics;

- At least two resistance sessions for large muscle groups (lower limbs, upper limbs and trunk) per week, respecting one to two days of recovery between two sessions. The intensity must be adapted to the individual characteristics and remain moderate. Simple bodyweight exercises may be sufficient;

- Flexibility and joint mobility exercises two or three times a week. They should be limited by the feeling of discomfort and stiffness;

- For older patients, balance exercises can be combined at least twice a week.

\subsubsection{Recommendations and options}

\section{RECOMMENDATIONS}

- Colorectal cancer (expert agreement):

- Encourage and support behavioral changesin order to increase PA level, gradually, maintained over time and regularly. PA practice includes spontaneous activities of daily living and structured voluntary exercise sessions, supervised or not;

- Objective of 150 minutes of moderate aerobic PA distributed throughout the week and two sessions per week of resistance exercises of large muscle groups (upper limbs, lower limbs and trunk) while respecting one to two days of recovery between two sessions.

- All tumor locations (expert agreement):

- Education and information of the patient on the benefits of PA after treatment (reduction of fatigue, improvement of HRQoL, and of physical fitness, potential effect on the risk of recurrence and survival), from the consultation for disease announcement;

- Limit sedentary behaviors (sitting or bedtime) and encourage regular PA (progressive implementation and taking into account the after-effects of treatments), combining aerobic and resistance exercises.

OPTIONS 
- Refer to an APA professional in particular for patients with barriers to practice: comorbidities, intense fatigue and/or significant and recent drop in the PA level, negative beliefs and fears about PA (expert opinion). 


\section{TABLES AND FIGURES}

Tables

Table 1. Prevalence of malnutrition in digestive cancers: NUTRICANCER studies $[1,2]$

\begin{tabular}{|l|l|}
\hline Tumor location & Prevalence \\
\hline All cancers & $39 \%$ \\
& $\begin{array}{l}\text { Metastatic stage: 42\% > Localized stage: } 27 \% \\
\text { ECOG-PS 4: 65 \% >PS 2-3: } 53 \%>\text { PS 1: } 31 \%>\text { PS 0: } 14 \%\end{array}$ \\
\hline Pancreas & $54-67 \%$ \\
\hline Esophagus/Stomach & $53-60 \%$ \\
\hline Liver & $55 \%$ \\
\hline Colon/rectum & $35-39 \%$ \\
\hline
\end{tabular}

ECOG-PS: Eastern Cooperative Oncology Group Performance Status

Table 2. Etiological factors of malnutrition in digestive cancers [3]

\begin{tabular}{|l|}
\hline Mechanisms \\
\hline (i) decrease in food intake, itself of multifactorial origin \\
\hline (ii) side effects of chemotherapy and radiotherapy (nausea, vomiting, taste and smell disturbances, \\
mucositis, diarrhea and colitis of various mechanisms, loss of appetite, malabsorption) \\
\hline (iii) sequelae from surgery (in particular, upper gastrointestinal tract and pancreatic surgery) \\
\hline (iv) tumor-induced inflammatory and hypercatabolic syndrome \\
\hline (v) digestive tract obstruction (by the primary tumor or peritoneal carcinomatosis) \\
\hline (vi) cholestasis and exocrine pancreatic insufficiency \\
\hline
\end{tabular}

Table 3. Grade of recommendations according to the GRADE system [14, 15]

\begin{tabular}{|l|l|l|}
\hline Grade & $\begin{array}{l}\text { Quality of } \\
\text { evidence }\end{array}$ & Definition \\
\hline A & High & $\begin{array}{l}\text { Strongly recommended based on highly robust scientific evidence (e.g. } \\
\text { several randomized controlled trials/meta-analysis) } \\
\text { Further research is very unlikely to change our confidence in the } \\
\text { estimate of effect }\end{array}$ \\
\hline B & Moderate & $\begin{array}{l}\text { Usually recommended based on scientific presumption (e.g. one } \\
\text { randomized controlled trial) } \\
\text { Further research is likely to have an important impact on our confidence } \\
\text { in the estimate of effect and may change the estimate }\end{array}$ \\
\hline C & Low & $\begin{array}{l}\text { Option based on weak scientific evidence (e.g. one or several non- } \\
\text { randomized trials) }\end{array}$ \\
\hline D & Very low & Expert opinion (agreement or not) \\
\hline
\end{tabular}

Table 4. National Institute for Health and Care Excellence (NICE) guidelines for identification of patients at high risk for refeeding syndrome [26]

\begin{tabular}{|l|l|}
\hline $\begin{array}{l}\text { Patient has one or more } \\
\text { major criteria }\end{array}$ & $\begin{array}{l}\text { Patient has two or more } \\
\text { major criteria }\end{array}$ \\
\hline
\end{tabular}




\begin{tabular}{|l|l|}
\hline $\mathrm{BMl}<16 \mathrm{~kg} / \mathrm{m}^{2}$ & $\mathrm{BMl}<18.5 \mathrm{~kg} / \mathrm{m}^{2}$ \\
\hline $\begin{array}{l}\text { Unintentional weight loss of }>15 \% \text { in the } \\
\text { previous 3-6months }\end{array}$ & $\begin{array}{l}\text { Unintentional weight loss of }>10 \% \text { in the } \\
\text { previous 3-6 months }\end{array}$ \\
\hline Little or no nutritional intake for $>10$ days & Little or no nutritional intake for $>5$ days \\
\hline $\begin{array}{l}\text { Low levels of potassium, phosphorus, or } \\
\text { magnesium before refeeding }\end{array}$ & $\begin{array}{l}\text { History of alcohol misuse or drugs, including } \\
\text { insulin, chemotherapy, antiacids, or diuretics }\end{array}$ \\
\hline
\end{tabular}

BMI: body mass index

Table 5. Nutritional risk stratification in the perioperative setting

\begin{tabular}{|l|l|}
\hline Nutritional grade 1(NG 1) & $\begin{array}{l}\text { Non malnourished patient } \\
\text { AND no risk factor of malnutrition } \\
\text { AND surgery with low risk of morbidity }\end{array}$ \\
\hline Nutritional grade 2(NG 2) & $\begin{array}{l}\text { Non malnourished patient } \\
\text { AND at least one risk factor of mal nutrition OR surgery with high risk } \\
\text { of morbidity }\end{array}$ \\
\hline Nutritional grade 3(NG 3) & $\begin{array}{l}\text { Malnourished patient } \\
\text { AND surgery with low risk of morbidity }\end{array}$ \\
\hline Nutritional grade 4(NG 4) & $\begin{array}{l}\text { Malnourished patient } \\
\text { AND surgery with high risk of morbidity }\end{array}$ \\
\hline
\end{tabular}

Table 6. Guidelines for perioperative management according to nutritional status

\begin{tabular}{|c|c|c|}
\hline & $\begin{array}{l}\text { Non malnourished patients } \\
\text { (Nutritional grade 2) }\end{array}$ & $\begin{array}{l}\text { Malnourished patients (Nutritional } \\
\text { grade 4) }\end{array}$ \\
\hline Pre-operative & $\begin{array}{l}\text { - Evaluation of oral intake (VAS of food } \\
\text { intake) } \\
\text { - If oral intake is reduced (VAS }<7) \text { : } \\
\text { dietary advice and oral nutritional } \\
\text { supplements with high calorie or high } \\
\text { protein content ( } 2 / \text { day as a snack } \\
\text { away from meals) } \\
\text { - Oral Impact }{ }^{\circledR}: 3 \text { vials }(250 \mathrm{~mL} \text { ) per } \\
\text { day, away from meals, for } 5 \text { to } 7 \text { days } \\
\text { before the surgery }\end{array}$ & $\begin{array}{l}\text { - Nutritional support for } 7 \text { to } 14 \\
\text { days, via enteral route rather than } \\
\text { parenteral route whenever possible } \\
\text { - Oral Impact }{ }^{\oplus}: 3 \text { vials ( } 250 \mathrm{~mL} \text { ) per } \\
\text { day for } 5 \text { to } 7 \text { days, away from meals, } \\
\text { before surgery; use Impact }{ }^{\circledR} \text { Enteral } \\
(1,000 \mathrm{~mL} \text { ) if oral route is not possible }\end{array}$ \\
\hline $\begin{array}{l}\text { Immediate pre- } \\
\text { operative }\end{array}$ & $\begin{array}{l}\text { - Limitation of the duration of the fast: } \\
\text { light meal the day before the } \\
\text { operation and administration the day } \\
\text { before }(2 \times 400 \mathrm{~mL}) \text { and the morning of } \\
\text { the operation }(400 \mathrm{~mL} \text { ) of a clear sugar } \\
\text { solution with low osmolarity ( } 50 \mathrm{~g} \text { of } \\
\text { glucose } / 400 \mathrm{~mL}) \text {; fast } 2 \text { hours for } \\
\text { liquids and } 6 \text { hours for solids }\end{array}$ & $\begin{array}{l}\text { - Limitation of the duration of the } \\
\text { fast: light meal the day before the } \\
\text { operation and administration the day } \\
\text { before }(2 \times 400 \mathrm{~mL} \text { ) and the morning } \\
\text { of the operation }(400 \mathrm{~mL} \text { ) of a clear } \\
\text { sugar solution with low osmolarity } \\
\text { ( } 50 \mathrm{~g} \text { of glucose } / 400 \mathrm{~mL}) \text {; fast } 2 \text { hours } \\
\text { for liquids and } 6 \text { hours for solids }\end{array}$ \\
\hline Post-operative & $\begin{array}{l}\text { - Early oral feeding started within } 24 \\
\text { hours at the latest (in the absence of } \\
\text { surgical contraindication), except in } \\
\text { case of esophageal anastomosis } \\
\text { - In the absence of oral food: } \\
\text { intravenous intake of } 1.5 \text { to } 2.5 \mathrm{~L} / 24 \mathrm{~h} \\
\text { of } 5 \% \text { glucose solution }+3 \text { to } 6 \mathrm{~g} \text { ( } 50 \text { - }\end{array}$ & $\begin{array}{l}\text { - Early oral feeding started within } 24 \\
\text { hours at the latest (in the absence of } \\
\text { surgical contraindication), except in } \\
\text { case of esophageal anastomosis } \\
\text { - Systematicnutritional support, via } \\
\text { enteral route rather than parenteral } \\
\text { route whenever possible }\end{array}$ \\
\hline
\end{tabular}




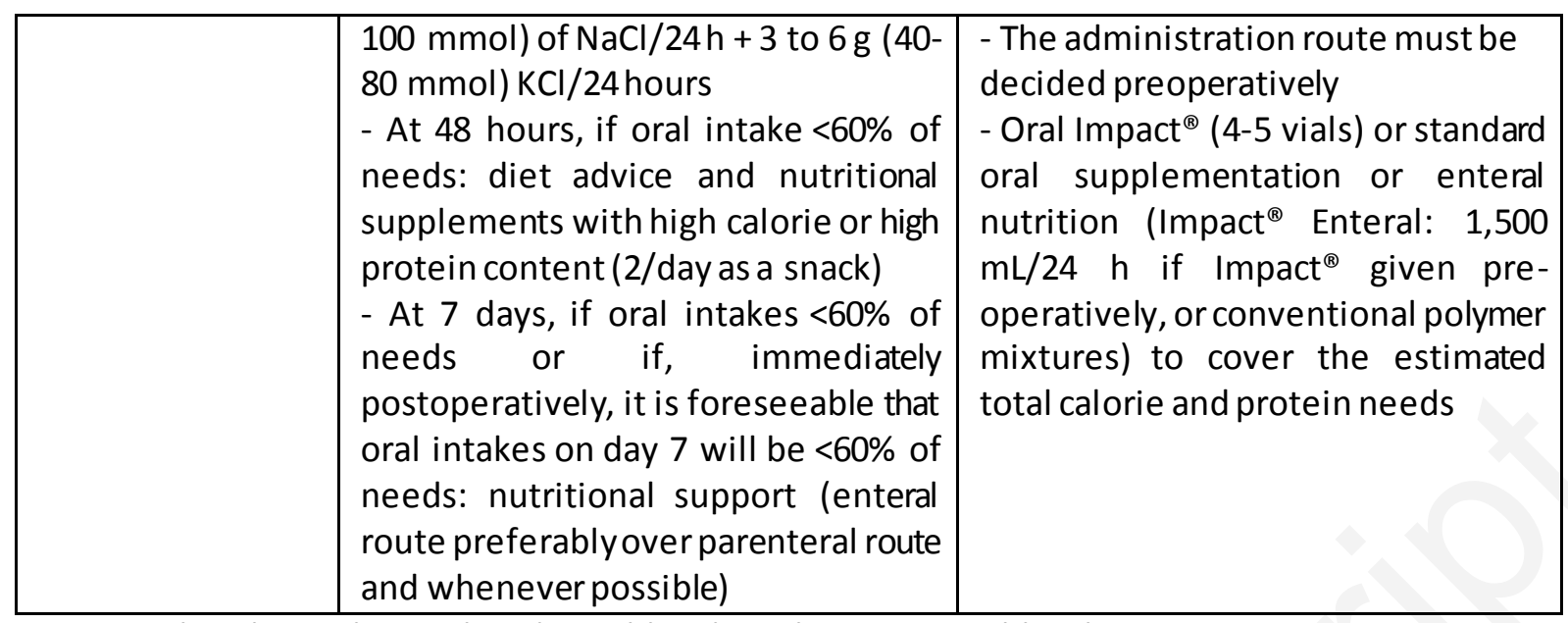

VAS: visual analog scale; $\mathrm{NaCl}$ : sodium chloride; $\mathrm{KCl}$ : potassium chloride

\section{Figure legends}

Figure 1. Algorithm summarizing the nutritional management during systemic treatments (adapted from Bouteloup C. \& Thibault R.) 


\section{Conflict of interest}

- C Neuzillet: Consultancy/honoraria: Pierre Fabre, Servier, Roche, AstraZeneca, Bristol-Myers Squibb, Amgen, Merck, MSD, Novartis, Incyte Biosciences, Mylan, Baxter, Nutricia, Fresenius Kabi; Research funding: Roche; Clinical trials: OSE Immunotherapeutics, AstraZeneca, Bristol-Myers Squibb, Merus - A.M. Foucaut: Pierre Fabre, Ceformed, MéthodCO

- E. Fontaine: Baxter, Nutricia, Fresenius Kabi, Aguettant, BBraun

- X. Hébuterne: clinical research funding from AbbVie; Abivax; Alphasigma; Celgene; Gilead Science, Inc; Eli Lilly; Enterome, Janssen; InDex Pharmaceuticals; Pfizer; Roche; Salix; Takeda; Theravance; advisory boards for AbbVie, Arena Pharmaceuticals, Arkopharma, Astellas, Janssen, Nutricia, Pfizer, Sangano, Takeda; lectures and educational activities for AbbVie, Baxter, Bristol-Myers Squibb, Ferring, Janssen, MSD, Mylan, Nutricia, Pfizer, Sanofi-Advantis, Tillots, and Takeda

- A. Lièvre: grants from Bayer Lilly, Merck and Novartis; personal fees from AAA, Amgen, Bayer, BristolMyers Squibb, Celgene, HalioDx, Incyte, Ipsen, Lilly, Merck, Novartis, Pierre Fabre, Roche, Sandoz, Sanofi and Servier; non financial support from AAA, Amgen, Bayer, Incyte, Ipsen, Merck, Novartis, Pierre Fabre, Pfizer, Roche, Sandoz, Servier and Integragen

- T. Mouillot: Baxter, Nutricia, Nestle

- B. Raynard: honoraria from Fresenius Kabi for Scientific Board (NUTRICANCER2 and SCAN stu dies)

- S. Schneider: Baxter, B. Braun, Fresenius-Kabi, Laboratoires Grand-Fontaine, Nestlé Health Science, Nutricia

- D. Vansteene: Fresenius Kabi, Nutricia, Nestle Health Science

- O. Bouché: Merck KGaA, Roche, Bayer, Astra-Zeneca, Grunenthal, MSD, Amgen, Servier, Pierre Fabre - A. Anota, A.L. Védie, S. Antoun, D. Barnoud, C. Bouleuc, F. Chorin, V. Cottet, V. Garabige, F. Huguet, T. Marchal, D. Quilliot, F. Peschaud, F. Scotté, P. Mariani, F. Joly have reported no potential conflicts of interest.

\section{Acknowledgements}

We thank the review committee: Damien Botsen (Reims), Corinne Bouteloup (Clermont-Ferrand), Thérèse Delebecq (Roubaix), Aurélien Dupré (Lyon), Serge Fratte (Belfort), Lucie Gentilhomme (Paris), Radwan Kassir (Saint-Denis), Dine Koriche (Béthune), Antoine Lortholary (Marseille), Nicolas Mocelin (Thionville), Yann Mottaz (Blois), Guillaume Passot (Lyon), Cyril Perrenot (Reims), Stéphanie Truant (Lille), Anthony Turpin (Lille). 


\section{REFERENCES}

1. Gyan E, Raynard B, Durand JP et al. Malnutrition in Patients With Cancer: Comparison of Perceptions by Patients, Relatives, and Physicians-Results of the NutriCancer2012 Study. JPEN J Parenter Enteral Nutr 2018; 42: 255-260.

2. Hebuterne X, Lemarie E, Michallet $M$ et al. Prevalence of malnutrition and current use of nutrition support in patients with cancer. JPEN J Parenter Enteral Nutr 2014; 38: 196-204.

3. Arends J, Baracos V, Bertz H et al. ESPEN expert group recommendations for action against cancer-related malnutrition. Clin Nutr 2017; 36: 1187-1196.

4. Prado CM, Lieffers JR, McCargar LJ et al. Prevalence and clinical implications of sarcopenic obesity in patients with solid tumours of the respiratory and gastrointestinal tracts: a population-based study. Lancet Oncol 2008; 9: 629-635.

5. Silva FR, de Oliveira MG, Souza AS et al. Factors associated with malnutrition in hospitalized cancer patients: a croos-sectional study. Nutr J 2015; 14: 123.

6. Cederholm T, Barazzoni R, Austin P et al. ESPEN guidelines on definitions and terminology of clinical nutrition. Clin Nutr 2017; 36: 49-64.

7. Hilmi M, Jouinot A, Burns R et al. Body composition and sarcopenia: The nextgeneration of personalized oncology and pharmacology? Pharmacol Ther 2019;196: 135 159.

8. Martin L, Senesse P, Gioulbasanis I et al. Diagnostic criteria for the classification of cancer-associated weight loss. J Clin Oncol 2015; 33: 90-99.

9. Haute Autorité de Santé. Diagnostic de la dénutrition de l'enfant et de l'adulte. RECOMMANDATION DE BONNE PRATIQUE 2019; https://www.hassante.fr/upload/docs/application/pdf/2019-

2011/reco2277 recommandations rbp denutrition cd 201920112013 v2010.pdf..

10. Schneider SM, Correia M. Epidemiology of weight loss, malnutrition and sarcopenia: A transatlantic view. Nutrition 2020; 69: 110581.

11. Cruz-Jentoft AJ, Bahat G, Bauer J et al. Sarcopenia: revised European consensus on definition and diagnosis. Age Ageing 2019; 48: 16-31.

12. Baracos VE, Mazurak VC, Bhullar AS. Cancer cachexia is defined by an ongoing loss of skeletal muscle mass. Ann Palliat Med 2019; 8: 3-12.

13. Fearon K, Strasser F, Anker SD et al. Definition and classification of cancer cachexia: an international consensus. Lancet Oncol 2011; 12: 489-495.

14. Guyatt GH, Oxman AD, Kunz R et al. Going from evidence to recommendations. BMJ 2008; 336: 1049-1051.

15. Guyatt GH, Oxman AD, Vist GE et al. GRADE: an emerging consensus on rating quality of evidence and strength of recommendations. BMJ 2008; 336: 924-926.

16. Guerdoux-Ninot E, Flori N, Janiszewski C et al. Assessing dietary intake in accordance with guidelines: Useful correlations with an ingesta-Verbal/Visual Analogue Scale in medical oncology patients. Clin Nutr 2019; 38: 1927-1935.

17. Poulia KA, Klek S, Doundoulakis I et al. The two most popular malnutrition screening tools in the light of the new ESPEN consensus definition of the diagnostic criteria for malnutrition. Clin Nutr 2017; 36: 1130-1135.

18. Mitsiopoulos N, Baumgartner RN, Heymsfield SB et al. Cadaver validation of skeletal muscle measurement by magnetic resonance imaging and computerized tomography. J Appl Physiol (1985) 1998; 85: 115-122.

19. Shen W, Punyanitya M, Wang Z et al. Total body skeletal muscle and adipose tissue volumes: estimation from a single abdominal cross-sectional image. J Appl Physiol (1985) 2004; 97: 2333-2338. 
20. Tomruk M, Karadibak D, Yavuzsen T, Akman T. Predictors of functional capacity in colorectal cancer patients. Support Care Cancer 2015; 23: 2747-2754.

21. www.ecog-acrin.org/resources/ecog-performance-status.

22. https://www.afsos.org/wp-

content/uploads/2019/05/AP_cancer_2018_AFSOS.pdf.

23. Botsen D, Ordan MA, Barbe C et al. Dynapenia could predictchemotherapy-induced dose-limiting neurotoxicity in digestive cancer patients. BMC Cancer 2018; 18: 955.

24. Ordan MA, Mazza C, Barbe $C$ et al. Feasibility of systematic handgrip strength testing in digestive cancer patients treated with chemotherapy: The FIGHTDIGO study. Cancer 2018; 124: 1501-1506.

25. Moreau J, Ordan MA, Barbe C et al. Correlation between muscle mass and handgrip strength in digestive cancer patients undergoing chemotherapy. Cancer Med 2019; 8: 3677-3684.

26. da Silva JSV, Seres DS, Sabino K et al. ASPEN Consensus Recommendations for Refeeding Syndrome. Nutr Clin Pract 2020; 35: 178-195.

27. Mislang AR, Di Donato S, Hubbard J et al. Nutritional management of older adults with gastrointestinal cancers: An International Society of Geriatric Oncology (SIOG) review paper. J Geriatr Oncol 2018; 9: 382-392.

28. Paillaud E, Soubeyran P, Caillet $P$ et al. Multidisciplinary development of the Geriatric Core Dataset for clinical research in older patients with cancer: A French initiative with international survey. Eur J Cancer 2018; 103: 61-68.

29. Martinez-Tapia C, Paillaud E, Liuu E et al. Prognostic value of the G8 and modifiedG8 screening tools for multidimensional health problems in older patients with cancer. Eur J Cancer 2017; 83: 211-219.

30. Kerr J, Anderson C, Lippman SM. Physical activity, sedentary behaviour, diet, and cancer: an update and emerging new evidence. Lancet Oncol 2017; 18: e457-e471.

31. Lauby-Secretan B, Scoccianti C, Loomis D et al. Body Fatness and Cancer-Viewpoint of the IARC Working Group. N Engl J Med 2016; 375: 794 -798.

32. Aparicio T, Ducreux M, Faroux R et al. Overweight is associated to a better prognosis in metastatic colorectal cancer: A pooled analysis of FFCD trials. Eur J Cancer 2018; 98: 1-9.

33. Caan BJ, Meyerhardt JA, Kroenke $\mathrm{CH}$ et al. Explaining the Obesity Paradox: The Association between Body Composition and Colorectal Cancer Survival (C-SCANS Study). Cancer Epidemiol Biomarkers Prev 2017; 26: 1008-1015.

34. Pamoukdjian F, Aparicio T, Canoui-Poitrine F et al. Obesity survival paradox in cancer patients: Results from the Physical Frailty in older adult cancer patients (PF-EC) study. Clin Nutr 2019; 38: 2806-2812.

35. Vaid S, Bell T, Grim R, Ahuja V. Predicting risk of death in general surgery patients on the basis of preoperative variables using American College of Surgeons National Surgical Quality Improvement Program data. Perm J 2012; 16: 10 -17.

36. Gibson TM, Park Y, Robien K et al. Body mass index and risk of second obesityassociated cancers after colorectal cancer: a pooled analysis of prospective cohortstudies. J Clin Oncol 2014; 32: 4004-4011.

37. Chambrier C, Sztark F, Societe Francophone de nutrition clinique et $\mathrm{m}$, Societe francaise d'anesthesie et $r$. French clinical guidelines on perioperative nutrition. Update of the 1994 consensus conference on perioperative artificial nutrition for elective surgery in adults. J Visc Surg 2012; 149: e325-336.

38. Hua $\mathrm{H}, \mathrm{Xu} \mathrm{X}$, Tang $\mathrm{Y}$ et al. Effect of sarcopenia on clinical outcomes following digestive carcinoma surgery: a meta-analysis. Support Care Cancer 2019; 27: 2385-2394. 
39. Senesse P, Bachmann P, Bensadoun RJ et al. SFNEP oncology nutrition guidelines: Summary of statements. Nutr Clin Metab 2012; 26: 151-158.

40. Weimann A, Braga M, Carli F et al. ESPEN guideline: Clinical nutrition in surgery. Clin Nutr 2017; 36: 623-650.

41. Deleenheer B, Declercq P, Van Veer H et al. Evaluation of parenteral nutrition use in patients undergoing major upper gastro-intestinal surgery. Int J Clin Pharm 2015; 37: 579-582.

42. Mazaki T, Ebisawa K. Enteral versus parenteral nutrition after gastrointestinal surgery: a systematic review and meta-analysis of randomized controlled trials in the English literature. J Gastrointest Surg 2008; 12: 739-755.

43. https://www.afsos.org/wp-content/uploads/2018/12/RIR-AFSOS- Diabete-etCancer vdef compressed.pdf.

44. https://www.e-cancer.fr/Expertises-et-publications/Catalogue-despublications/Benefices-de-l-activite-physique-pendant-et-apres-cancer-Desconnaissances-aux-reperes-pratiques.

45. Pecorelli N, Fiore JF, Jr., Gillis C et al. The six-minute walk test as a measure of postoperative recovery after colorectal resection: further examination of its measurement properties. Surg Endosc 2016; 30: 2199-2206.

46. West MA, Loughney L, Lythgoe D et al. Effect of prehabilitation on objectively measured physical fitness after neoadjuvant treatment in preoperative rectal cancer patients: a blinded interventional pilot study. Br J Anaesth 2015; 114: 244-251.

47. Minnella EM, Awasthi R, Loiselle SE et al. Effect of Exercise and Nutrition Prehabilitation on Functional Capacity in Esophagogastric Cancer Surgery: A Randomized Clinical Trial. JAMA Surg 2018; 153: 1081-1089.

48. Minnella EM, Bousquet-Dion G, Awasthi R et al. Multimodal prehabilitation improves functional capacity before and after colorectal surgery for cancer: a five-year research experience. Acta Oncol 2017; 56: 295-300.

49. Barberan-Garcia A, Ubre M, Roca J et al. Personalised Prehabilitation in High-risk Patients Undergoing Elective Major Abdominal Surgery: A Randomized Blinded Controlled Trial. Ann Surg 2018; 267: 50-56.

50. Gillis C, Li C, Lee L et al. Prehabilitation versus rehabilitation: a randomized control trial in patients undergoing colorectal resection for cancer. Anesthesiology 2014; 121 : 937-947.

51. Loughney L, West MA, Kemp GJ et al. Exercise intervention in people with cancer undergoing neoadjuvant cancer treatment and surgery: A systematic review. Eur J Surg Oncol 2016; 42: 28-38.

52. Loughney L, West MA, Kemp GJ et al. Exercise intervention in people with cancer undergoing adjuvant cancer treatment following surgery: A systematic review. Eur J Surg Oncol 2015; 41: 1590-1602.

53. Spaander MC, Baron TH, Siersema PD et al. Esophageal stenting for benign and malignant disease: European Society of Gastrointestinal Endoscopy (ESGE) Clinical Guideline. Endoscopy 2016; 48: 939-948.

54. Arends J, Bachmann P, Baracos V et al. ESPEN guidelines on nutrition in cancer patients. Clin Nutr 2017; 36: 11-48.

55.

https://www6.inrae.fr/nacre/content/download/5448/46454/version/4/file/R apport+NACRe-Jeûne-regimes-restrictifs-cancer_2017_2018.02.06.pdf.

56. https://www.has-sante.fr/upload/docs/application/pdf/2008-07/cepp1333avisnutrition_parenteral_a_domicile.pdf. 
57. Cramp F, Byron-Daniel J. Exercise for the management of cancer-related fatigue in adults. Cochrane Database Syst Rev 2012; 11: CD006145.

58. Mishra SI, Scherer RW, Snyder C et al. Exercise interventions on health-related quality of life for people with cancer during active treatment. Cochrane Database Syst Rev 2012; CD008465.

59. van Waart H, Stuiver MM, van Harten WH et al. Effect of Low-Intensity Physical Activity and Moderate- to High-Intensity Physical Exercise During Adjuvant Chemotherapy on Physical Fitness, Fatigue, and Chemo therapy Completion Rates: Results of the PACES Randomized Clinical Trial. J Clin Oncol 2015; 33: 1918-1927.

60. Ashcraft KA, Peace RM, Betof AS et al. Efficacy and Mechanisms of Aerobic Exercise on Cancer Initiation, Progression, and Metastasis: A Critical Systematic Review of In Vivo Preclinical Data. Cancer Res 2016; 76: 4032-4050.

61. Guercio BJ, Zhang S, Ou FS et al. Associations of Physical Activity With Survival and Progression in Metastatic Colorectal Cancer: Results From Cancer and Leukemia Group B (Alliance)/SWOG 80405. J Clin Oncol 2019; 37: 2620-2631.

62. Mustian KM, Alfano CM, Heckler $\mathrm{C}$ et al. Comparison of Pharmaceutical, Psychological, and Exercise Treatments for Cancer-Related Fatigue: A Meta-analysis. JAMA Oncol 2017; 3: 961-968.

63. Van Blarigan EL, Meyerhardt JA. Role of physical activity and diet after colorectal cancer diagnosis. J Clin Oncol 2015; 33: 1825-1834.

64. Bouleuc C, Anota A, Cornet C et al. Impact on Health-Related Quality of Life of Parenteral Nutrition for Patients with Advanced Cancer Cachexia: Results from a Randomized Controlled Trial. Oncologist 2020; 25: e843-e851.

65. Matthews CE, Moore SC, Arem $\mathrm{H}$ et al. Amount and Intensity of Leisure-Time Physical Activity and Lower Cancer Risk. J Clin Oncol 2020; 38: 686-697.

66. Schmid D, Leitzmann MF. Association between physical activity and mortality among breast cancer and colorectal cancer survivors: a systematic review and metaanalysis. Ann Oncol 2014; 25: 1293-1311. 